\title{
Effect of Residual Stress Relaxation due to Sample Extraction on the Detectability of Hot Crack Networks in LTT Welds by means of $\mu \mathrm{CT}$
}

\author{
F. Vollert ${ }^{1, a^{*}}$, J. Dixneit ${ }^{2, b}$ and J. Gibmeier ${ }^{1, c}$ \\ ${ }^{1}$ Karlsruhe Institute of Technology (KIT), Institute of Applied Materials (IAM), Kaiserstr.12, 76131 \\ Karlsruhe, Germany \\ ${ }^{2}$ Bundesanstalt für Materialforschung und -prüfung (BAM), Unter den Eichen 87, 12205 Berlin, \\ Germany \\ aflorian.vollert@kit.edu, bjonny.dixneit@bam.de, cjens.gibmeier@kit.edu
}

Keywords: LTT Weld Filler Materials, $\mu$ CT-analysis, Hot Cracks, Welding

\begin{abstract}
Investigations on weldability often deal with hot cracking as one of the most prevalent failure mechanisms during weld fabrication. The modified varestraint transvarestraint hot cracking test (MVT) is well known to assess the hot cracking susceptibility of materials [1, 2]. The shortcoming of this approach is that the information is only from the very near surface region which inhibits access to the characteristic of the hot crack network in the bulk. Here, we report about an alternative approach to monitor the entire 3D hot crack network after welding by means of microfocus X-ray computer tomography $(\mu \mathrm{CT})$. However, to provide sufficient high spatial resolution small samples must be sectioned from the MVT-welded joint. The sampling is accompanied by local relaxation of the residual stress distributions that are induced by welding, which can have an impact on the crack volumes prior to the sampling. The studies were carried out to investigate the hot cracking susceptibility of low transformation temperature filler materials (LTT) [3, 4]. As high compression residual stresses up to $-600 \mathrm{MPa}$ in the area of the crack networks were determined by means of the contour method, stress relaxation caused by sectioning for $\mu \mathrm{CT}$ sample extraction can affect the detectability of the cracks later on. X-ray diffraction studies revealed surface residual stress relaxations up to about $400 \mathrm{MPa}$ due to cutting. To investigate this effect, the specimens with hot cracks were subjected to a load test with known stress states. The results clearly show that local stress relaxations will have a strong impact on the volume images reconstructed from tomography analysis. This effect must be considered during hot crack assessment on basis of $\mu \mathrm{CT}$ data.
\end{abstract}

\section{Introduction}

Using low transformation temperature (LTT) weld filler materials is an innovative method to mitigate welding tensile residual stresses directly during weld fabrication by means of a delayed martensite transformation and thus, the fatigue life will be increased without time consuming or cost intensive post-weld treatments $[5,6]$. However, LTT alloys are high alloyed filler materials and therefore may show high hot cracking susceptibilities dependent on the chemical composition. Measurements of the total crack length provided by $\mu \mathrm{CT}$ analysis in the MVT showed that the hot crack susceptibility of LTT alloys will be increased with increasing content of chrome and nickel, while the total crack length maximum will be in the weld depth [4]. As an appropriate approach to assess hot cracking, the standardised modified varestraint transvarestraint hot cracking test (MVT) was developed [1]. By means of this test different base or filler materials can easily be evaluated during welding while bending the specimen at the same time in the longitudinal or transversal directions to the weld line using defined bending rates. 
Hereby tungsten inert gas (TIG) welding is used to simulate the weld fabrication by means of different heat inputs. After welding the total length of all detectable cracks at the specimen surface is added up. Depending on the bending strain applied, the hot cracking susceptibility of the tested material will be ranked into 'safe against hot cracks', 'increasing hot crack susceptibility' and 'high hot crack susceptibility'. However, MVT does not consider a crack network in the bulk. Hence, for accurate assessment of the hot crack susceptibility of material volumes information shall also be considered in addition. Therefore, microfocus X-ray computer tomography $(\mu \mathrm{CT})$ was applied (Fig. 1a). This method allows describing the complete 3D hot crack network in regards to e.g. crack volume, crack length as a function of the distance to the surface (Fig. 1b) and crack orientation.

a)

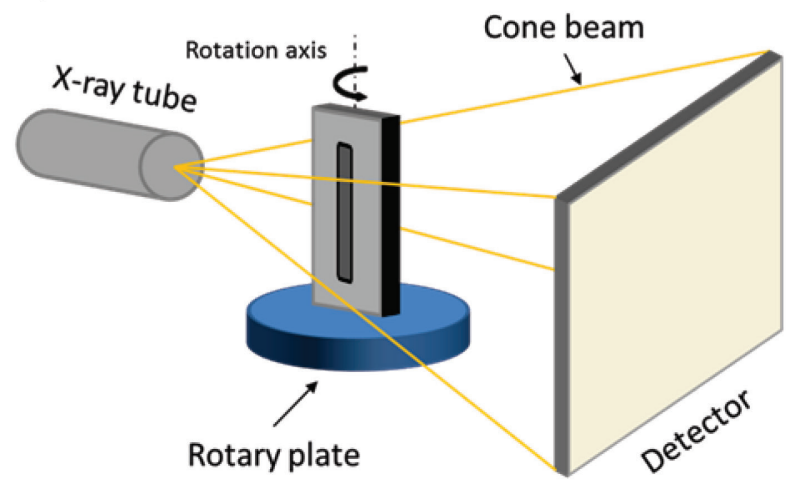

b)

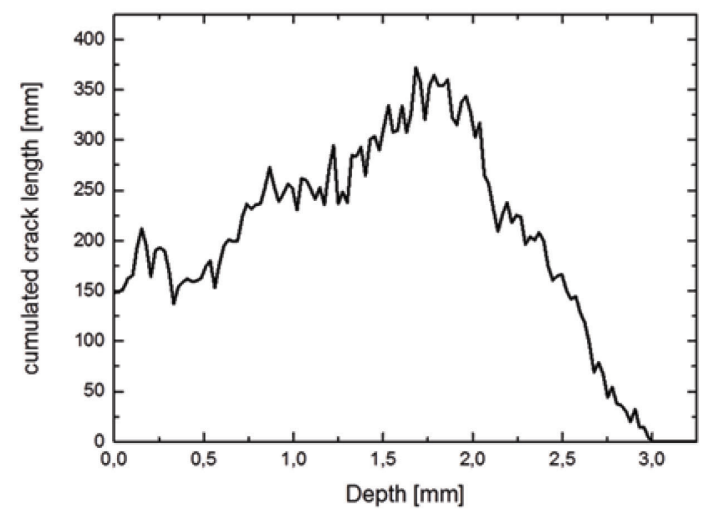

Fig. 1: Schematic illustration of the $\mu C T$-scan of the whole specimen to obtain the position of the hot crack network (a). As an example, the cumulated total crack length as a function of depth for the investigated specimen determined by $\mu C T$ is plotted (b).

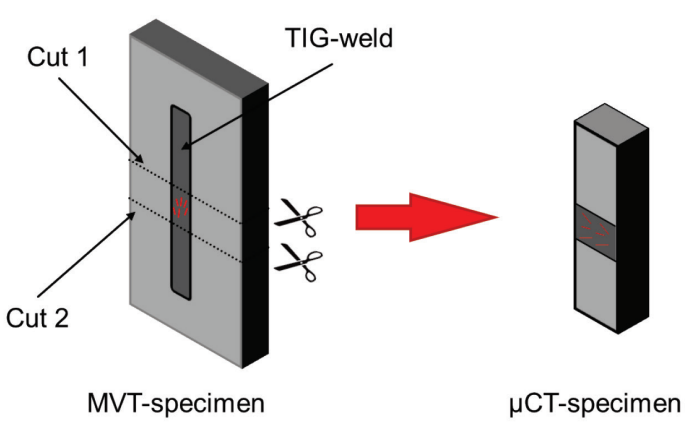

Fig. 2: Sample preparation for $\mu C T$ studies with initial MVT-specimen (left) and $\mu C T$ specimen (right). Location of hot cracks are indicated in red.
To provide a sufficient high resolution and to reduce X-ray absorption of the specimen it is necessary to cut the investigated specimen into smaller cuboids (Fig. 2). Because of the cone beam used in lab CT analysis (see Fig. 1a) the image resolution becomes better the closer the specimen can be positioned to the X-ray tube, which requires tailored and adequate specimen dimensions. However, the cutting process leads to residual stress relaxation in the region of the crack network, which may alter the results. In this paper we investigate the effect of residual stress relaxations on the visibility of cracks in the volume images re-constructed from $\mu \mathrm{CT}$ scans. 


\section{Experimental}

Material and specimen geometry. The investigated samples were standardised MVT specimens with dimensions $100 \times 40 \times 10 \mathrm{~mm}^{3}$. Prior to testing along the MVT welding direction a Ushaped groove with a depth of $5 \mathrm{~mm}$ and a width of $20 \mathrm{~mm}$ was milled into the blocks. The LTT alloy was deposited into the groove by manual gas metal arc welding using six layers while the low alloyed high strength steel S960Q was used as a substrate to reduce the amount of filler material. After welding the specimens were finished to the standardised MVT dimensions to account for the weld reinforcement. The chemical composition is shown in Table 1. During the MVT the LTT welds were re-melted by automated TIG-welding using a heat input of $7.5 \mathrm{kJcm}^{-1}$. Bending of the MVT specimens were executed during welding in the longitudinal direction to the weld line (varestraint-modus) using a bending radius of $125 \mathrm{~mm}$ (resulting surface strain of $4 \%$ ). A $\mu \mathrm{CT}$-scan of the whole MVT-specimen was performed to obtain the position of the hot crack network (Fig. 1a).

Table 1: Chemical composition in wt.\% of the pure LTT alloy and the base material determined by spectral analysis.

\begin{tabular}{|c|c|c|c|c|c|c|c|c|}
\hline \multirow{2}{*}{ Material } & \multicolumn{7}{|c|}{ Chemical composition in wt.\% } \\
\cline { 2 - 10 } & $\mathrm{C}$ & $\mathrm{Cr}$ & $\mathrm{Ni}$ & $\mathrm{Si}$ & $\mathrm{Mn}$ & $\mathrm{Mo}$ & $\mathrm{V}$ & $\mathrm{Fe}$ \\
\hline LTT weld & 0.11 & 6.5 & 7.9 & - & 0.59 & - & - & bal. \\
\hline S960Q (base material) & 0.18 & 0.8 & 2.0 & 0.5 & 1.6 & 0.6 & 0.1 & bal. \\
\hline
\end{tabular}

Residual stress measurements. Residual stress measurements were performed using the contour method developed by M. Prime [e.g. 7]. Here, the investigated specimen was cut at a chosen measuring plane (49 $\mathrm{mm}$ distance to specimen edge) using electric discharge machining (EDM). Afterwards the resultant deformation caused by residual stress relaxation at the newly created surface was measured by a coordinate measuring machine (CCM). The measured deformations are transferred to a finite element (FE) model and a linear elastic stress analysis performed in order to calculate a residual stress map of the stress component normal to the cut surface. This method is a well-suited technique for the investigated specimens as it gives an entire 2D residual stress map of the whole weld joint. In this paper the longitudinal residual stress component of one MVT-specimen was determined. Therefore, a cut in the transverse direction to the weld line was carried out using EDM with a brass wire of diameter $0.3 \mathrm{~mm}$. The specimen was clamped as close as possible to the cut to prevent sample movement. Afterwards the two cut surfaces were measured using the CCM type PRISMO navigator from Zeiss. A clamping styli with a ruby sphere (diameter $=0.67 \mathrm{~mm}$ ) was used with measuring point spacing set to $0.1 \mu \mathrm{m}$. The deformation data of both cut surfaces were averaged and obvious outliers removed. The resultant displacements were transferred as boundary conditions to a FE model of the investigated specimen. With Abaqus ${ }^{\circledR}$ a fully elastic FE stress analysis using Young's modulus of $210 \mathrm{GPa}$ and Poisson's ratio of 0.3 was performed. The results provide the initial residual stress state before cutting.

$\mu \mathrm{CT}$ load test. The load test was carried out using a load specimen, which was prepared out of the weld of an additionally tested MVT-specimen. The load specimen (Fig. 3 left) was cut out in the region of the cracks (determined by the $\mu \mathrm{CT}$-scan before) using EDM. A load testing machine (Fig. 3 right) specifically developed for $\mu \mathrm{CT}$-studies was used to investigate the effect of known stress states on the crack network. 9 load steps of compressive stress from $0 \mathrm{MPa}$ up to $-325 \mathrm{MPa}$ were applied to the specimen. 

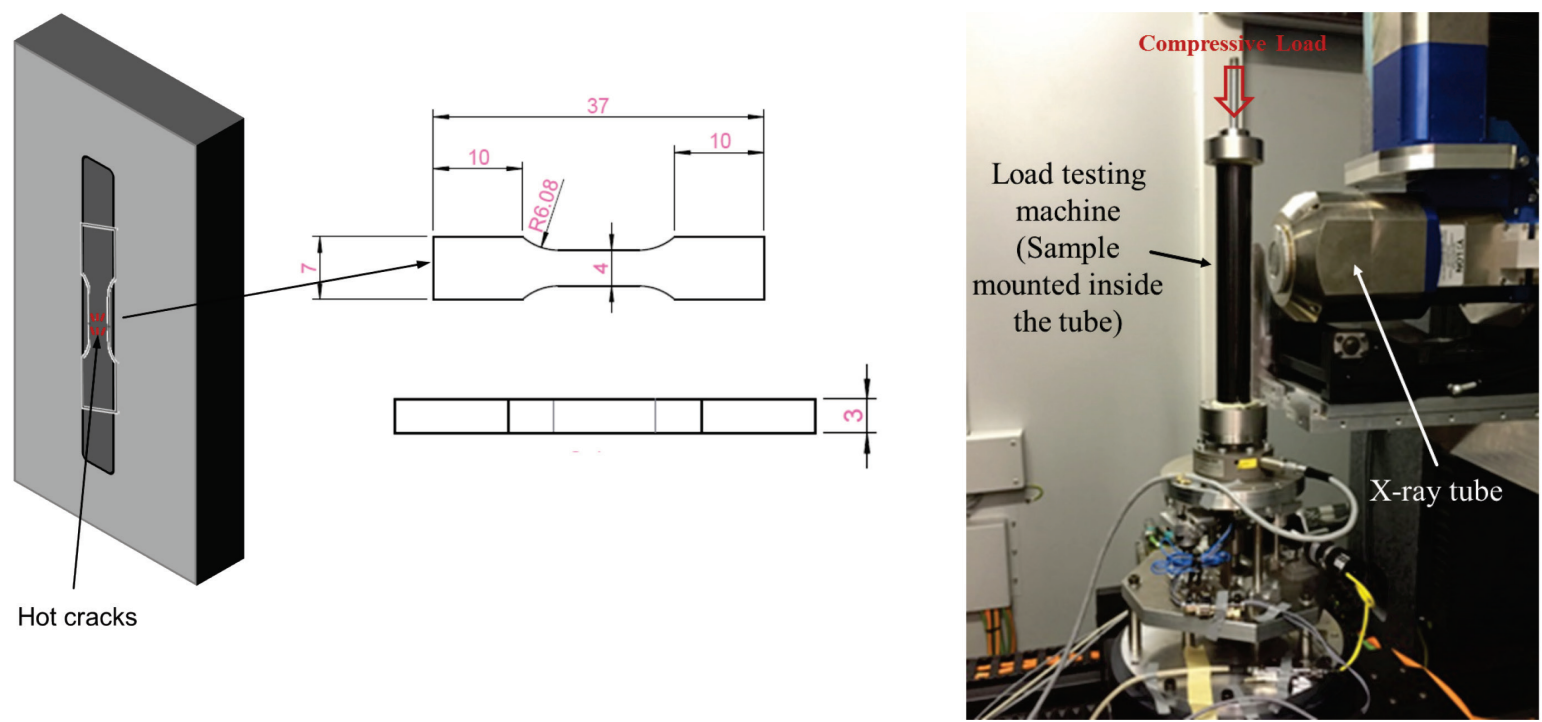

Fig. 3: Removal position of the load specimen for the load test (left). Load testing machine applied for the in-situ loading $\mu C T$-studies (right).

During each load step a $\mu \mathrm{CT}$-scan was performed while keeping the load at a constant level. The $\mu \mathrm{CT}$-scans were done using a $\mu \mathrm{CT}$ system type Y.CT.Precision (Yxlon 1td., Hamburg, Germany) with tube voltage and current set to $160 \mathrm{kV}$ and $0.05 \mathrm{~mA}$, respectively, providing a maximum resolution of about $1 \mu \mathrm{m}$ voxel size. Here, to get maximal high resolution, the load testing machine is positioned as close as possible to the X-ray tube resulting in a voxel size of $25 \mu \mathrm{m}$. The 3D images of the crack network were segmented into crack or base material using an adaptive threshold algorithm [8]. An adapted watershed algorithm [9], using the cracks determined by the adaptive thresholding algorithm as seeds, was then performed. This segmentation approach with defined thresholds ensures comparability between the different load steps. The segmented volume images can then be used to describe the hot crack network in regard to e.g. total crack volume and crack length as a function of applied stress.

\section{Results and Discussion}

Figure 4 displays the residual stress map for the longitudinal component determined by the contour method where the sample was cut perpendicular to the weld line. Compressive residual stresses up to approximately $-600 \mathrm{MPa}$ are present in the re-melted LTT weld. The region of compressive residual stresses extends down to a depth of approximately $4 \mathrm{~mm}$. Balancing tensile residual stresses up to $600 \mathrm{MPa}$ enclose the area of compressive residual stresses. The $\mu \mathrm{CT}$-scan of the whole MVT-specimen (prior to cutting the specimen for the load test) revealed that the complete hot crack network is located in the compressive residual stress area. X-ray diffraction studies revealed surface residual stress relaxation up to about $400 \mathrm{MPa}$ due to the cutting process. It may therefore be assumed that residual stress relaxation occurs in the region of the hot cracks. Figure 5 shows the 3D hot crack network in the tensile specimen before load was applied. The evaluation of the total crack network based on $\mu \mathrm{CT}$ data showed a decrease of total crack volume with increasing compressive stress (Fig. 6a). To investigate the reason of this effect, studies on individual cracks were performed. These cracks (mean crack lengths approx. $250 \mu \mathrm{m}$ ) have been selected based on their orientation to the load direction. The focus was set on two cracks and their behaviours when compressive stress was applied. One crack is oriented at 0 degrees (load type: mode III) and the other at 90 degrees (load type: mode I) to the load direction (Fig. 5). 


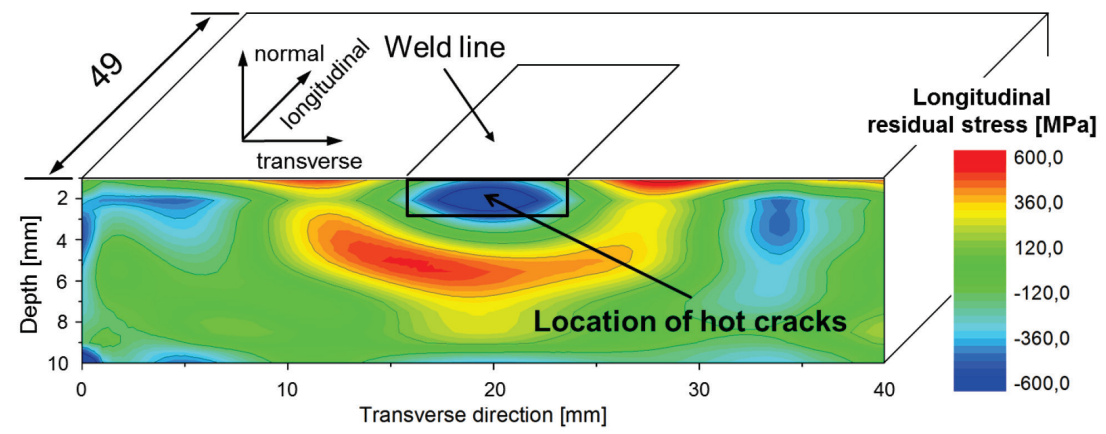

Fig. 4: Residual stress map of the longitudinal component determined by the contour method.

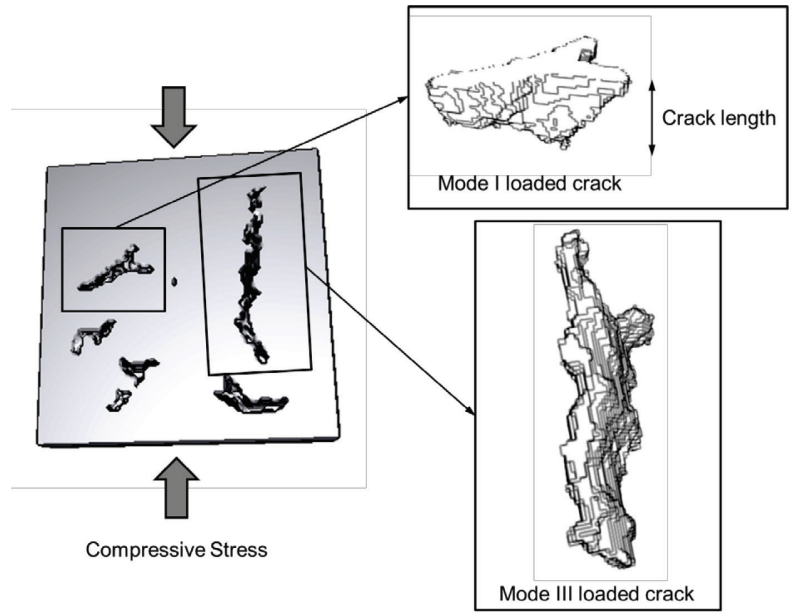

Fig. 5: 3D hot crack network to be found in the tensile specimen and the two investigated cracks (mode I and mode III loaded).

stresses are.

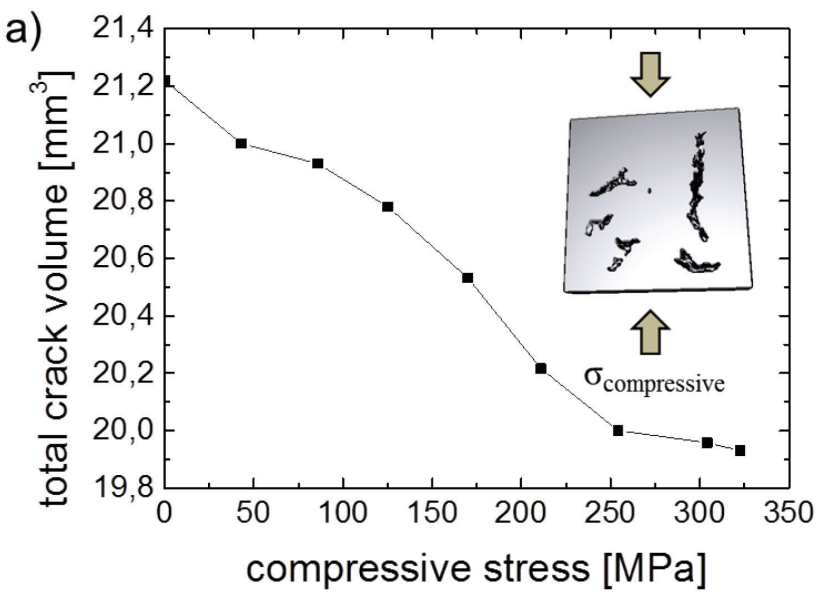

Analysis of the crack volume as a function of applied load leads to no measurable volume change for the mode III crack. However, the loaded mode I crack shows a decrease in crack volume with increasing compressive stress. A detailed observation reveals that the volume change is caused by the change in crack length (Fig. 6b). Apparently, increasing compressive stress leads to crack closure. The distance between opposing crack surfaces needs to be large enough to have an influence on the X-ray absorption and thus on the detectability in the reconstructed image. Therefore, the crack length seems to decrease in the $\mu \mathrm{CT}$ images, the higher the applied compressive

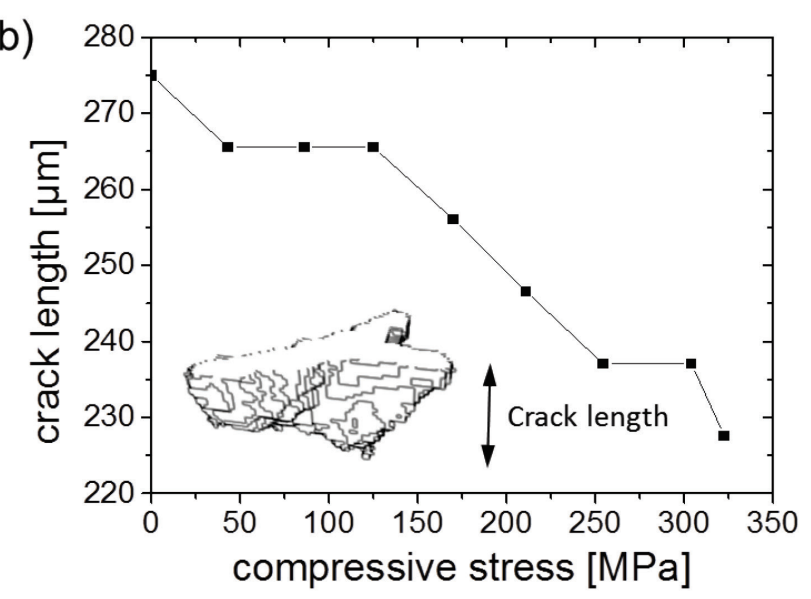

Fig. 6: Total crack volume as a function of the applied compressive stress (a) and crack length of the mode I loaded crack as a function of the applied compressive stress (b).

As a result, high compressive residual stresses in the region of the hot crack network can affect the detectability of the true crack length. Assuming that the actual crack length remains constant during sample preparation, in the case of compressive residual stresses in LTT-welds, 
cutting of the MVT-specimens and the resultant compressive residual stress relaxation may have a positive effect to determine the true total crack length using $\mu \mathrm{CT}$.

\section{Conclusion}

The effect of residual stresses on the detectability of hot cracks using $\mu \mathrm{CT}$ was investigated. The following major statements can be derived:

- Compressive residual stresses that are present in LTT-welds of MVT test samples relax during sample preparation for $\mu \mathrm{CT}$ and affect the detectability of hot cracks.

- The total crack length seems to be underestimated in presence of compressive residual stresses in the weld as the crack surfaces are pressed together and therefore the entire crack length is not determinable in reconstructed images.

- Compression tests revealed that the detectability of the crack length of cracks oriented 90 degrees to the load direction is strongly affected, while cracks oriented 0 degrees to the load direction show no significant effect.

- Furthermore, the $\mu \mathrm{CT}$ studies showed that providing the $3 \mathrm{D}$ crack network results are a much better basis for the assessment of the hot crack susceptibility in contrast to the conventional MVT test, which only focus on surface information.

\section{Acknowledgement}

Financial support by the German Research Foundation (DFG) in the projects GI376/8-1 is gratefully acknowledged.

\section{References}

[1] DIN EN ISO 17641: Destructive tests on welds in metallic materials - hot cracking tests for weldments, part 1, 3 - arc welding processes (2005)

[2] Th. Kannengiesser and Th. Boellinghaus, Hot cracking tests-an overview of present technologies and applications, Weld World 58 (2014) 397-421. https://doi.org/10.1007/s40194014-0126-y

[3] A. Ohta, O. Watanabe, K. Matsuoka, C. Siga, S. Nishijima, Y. Maeda, N. Suzuki and T. Kubo, Fatigue strength improvement by using newly developed low transformation temperature welding material, Welding in the World 43 (1999) 38-42.

[4] Th. Kannengiesser, M. Rethmeier, P.D. Portella, U. Ewert and B. Redmer, Assessment of hot cracking behaviour in welds, Int. J. Mater. Res. 102(8) (2011) 1-6. https://doi.org/10.3139/146.110545

[5] E. Harati, L. Karlsson, L.-E. Svensson and K. Dalaei, Applicability of low transformation temperature welding consumables to increase fatigue strength of welded high strength steels, Int. J. Fatigue 97 (2017) 39-47. https://doi.org/10.1016/j.ijfatigue.2016.12.007

[6] J. Gibmeier, E. Obelode, J. Altenkirch, A. Kromm and Th. Kannengießer, Residual stress in steel fusion welds joined using low transformation temperature (LTT) filler material. Mater. Sci. Forum 768-769 (2014) 620-627. https://doi.org/10.4028/www.scientific.net/MSF.768-769.620

[7] M.B. Prime and A.T. Dewald, Chapter 5 The contour method, in: G. S. Schajer (Ed.), Practical Residual Stress Measurement Methods, Wiley-Blackwell, 2013, pp. 109-138. https://doi.org/10.1002/9781118402832.ch5

[8] D. Bradley and G. Roth, Adaptive thresholding using the integral image, J. Graph. Tools 12 (2007) 13-21. https://doi.org/10.1080/2151237X.2007.10129236

[9] S. Beucher and C. Lantuejoul, Use of watersheds in contour detection, workshop on image processing, real-time edge and motion detection (1979) 